\title{
Study on Correlations Between Glycated Haemoglobin, Lipid Profiles and Blood Glucose Levels in Type 2 Diabetics Living at Moderate High Altitude
}

\author{
Rajashekar Rao Ba ${ }^{\mathrm{a}}$, Parineetha $\mathrm{PB}^{\mathrm{b}}$ and Venkata Raman Vc \\ a Department of Biochemistry, Melaka Manipal Medical College (Manipal Campus), International Centre for \\ Health Sciences, Manipal, India. 576104 \\ ${ }^{b}$ Department of Biochemistry, Jawaharlal Nehru Medical College, Belgaum- Karnataka. \\ c Department of Anatomy, Melaka Manipal Medical College (Manipal Campus), International Centre for \\ Health Sciences, Manipal, India. 576104
}

\begin{abstract}
Introduction: The study was conducted to look for the effects of polycythaemia on Glycosylated Haemoglobin (GHb) levels and to the see the correlations between the levels of haemoglobin, GHb, blood glucose, and lipid profiles including Atherogenic Index of plasma (AIP), in type 2 diabetics living $5800 \mathrm{ft}$ above sea level at Gangtok in Sikkim, India. GHb is used to predict the risk of long term complications of Diabetes mellitus (DM) like coronary artery disease (CAD). Materials and Methods: The study group consisted of Group I (Type 2 DM male patients with PPG levels $<200 \mathrm{mg} / \mathrm{dl}$ ), Group II (Type 2 DM male patients with PPG levels $>200 \mathrm{mg} /$ dl) and age matched healthy males formed the control group. Results: In Group I, GHb levels correlated positively with AIP, but not with TC/HDL-C ratio. In Group II, both PPG and GHb levels correlated positively with Total cholesterol (TC), LDL Cholesterol, TC IHDL-C ratio and AIP. This shows that higher PPG levels are associated with more Atherogenic lipid profiles. Study also showed higher GHb levels in controls at 7.61\%, and correlated positively with postprandial glucose (PPG) levels $(r=0.92)$. Conclusion: In predicting risk for future CAD, PPG levels and AIP can be used as an adjunct parameter.
\end{abstract}

KEYWORDS: Altitude, atherogenic index of plasma, glycosylated haemoglobin

\section{INTRODUCTION}

Diabetes mellitus is a systemic disease characterized by hyperglycaemia and the development of irreversible, invalidating and often mortal complications. ${ }^{1}$ With over 20 million diabetic subjects, India leads the world in the number of individuals with diabetes. ${ }^{2}$ India has thus become the "Diabetic Capital of the World". ${ }^{3}$

Of all the complications that beset diabetic subjects, the most dangerous and life threatening is coronary artery disease (CAD). Diabetic subjects have two or more folds higher risk for CAD compared to nondiabetic population. ${ }^{4}$ Despite the wide geographical variation in the prevalence of diabetes and CAD, the association of these two remains strong. Irrespective of the ethnic background, diabetic subjects have been shown to have high risk for CAD compared to the

Corresponding author;

Rajashekar Rao B

Department of Biochemistry,

Melaka Manipal Medical College (Manipal Campus), International Centre for Health Sciences,

Manipal-576104 Karnataka, India

e-mail: rajashekarraob@yahoo.co.in non-diabetic population. ${ }^{5}$ Several landmark studies in the west have revealed a strong association of CAD with plasma glucose levels. ${ }^{6-8}$ Chennai Urban Population Study which has been done in India has revealed that both fasting plasma glucose (FG) and $2 \mathrm{hr}$ post prandial plasma glucose (PPG) levels are strongly associated with CAD. ${ }^{9}$

\section{Diabetes Mellitus and Glycohaemoglobin}

Glycohaemoglobin (GHb, glycated haemoglobin, glycosylated haemoglobin) is a generic term for haemoglobin bound irreversibly (ketoamine form) to glucose. Total glycated haemoglobin (Total GHb) refers to all the glycated haemoglobins, including glycated haemoglobin variants. A1c is the nonenzymatic glycated product of the haemoglobin beta-chain at the valine terminal residue. The number $1 \mathrm{c}$ following $\mathrm{HbA}$ represents the order in which this haemoglobin is detected on chromatography. Hence, other haemoglobin peaks are referred to as HbA1a1, HbA1a2, HbA1b, and so forth. ${ }^{10}$ The A1c constitutes about $60-80 \%$ of total glycated haemoglobin. It is normally present, albeit at low levels, in circulating red cells because of the glycosylation reaction between haemoglobin and circulating glucose. ${ }^{11}$

In the presence of excess plasma glucose, the haemo- 
globin beta-chain becomes increasingly glycosylated, making the A1c a useful best indicator of glycaemia. ${ }^{2}$ The importance of A1c as an index of diabetes control was reinforced by the Diabetes Control and Complications Trial (DCCT). ${ }^{12}$ This study demonstrated a direct correlation between glycemic control as indicated by A1c and the likelihood of developing long-term diabetes-related complications. Current clinical recommendations of the American Diabetes Association suggest that $\mathrm{GHb}$ be maintained at $7 \%$, consistent with a decreased risk for developing long-term complications from diabetes mellitus. ${ }^{13} \mathrm{~A}$ reevaluation of the treatment regimen should be undertaken in patients with repeated $\mathrm{GHb}$ values $>8 \% .{ }^{14}$ Because $\mathrm{GHb}$ is based on haemoglobin, both qualitative and quantitative variations in haemoglobin can affect the GHb value. These factors need to be considered when interpreting $\mathrm{GHb}$ results and serve to limit the use of $\mathrm{GHb}$ as a diagnostic test for diabetes.

\section{Diabetes Mellitus and Dyslipidaemia}

In diabetes, there is a derangement in the metabolism of lipids and fat, which leads to abnormal serum lipid pattern. Dyslipidaemia has long been shown to have a strong relation with CAD. ${ }^{2}$ Type 2 diabetic patients have markedly increased risk of CAD than similarly dyslipidaemic non diabetic subjects. ${ }^{15}$ Low HDL Cholesterol, high LDL cholesterol, and high total and VLDL triglycerides, high Total cholesterol to HDL cholesterol (TC/HDL-C) ratio, are powerful risk indicators for coronary heart disease events in patients with type 2 diabetes mellitus. ${ }^{16,17}$

The Atherogenic Index of Plasma (AIP) has recently been proposed as a marker of plasma atherogenicity because it is increased in people at higher risk for coronary heart disease and is inversely correlated with LDL particle size. ${ }^{18}$ AIP is calculated as log (TG/ HDL-C), with TG and HDL-C expressed in molar concentrations. ${ }^{19}$ Previous studies suggest that AIP values of -0.3 to 0.1 are associated with low CAD risk, 0.1 to 0.24 medium and above 0.24 high risk. AIP can be easily calculated from standard lipid profile. As a marker of lipoprotein particle size it adds predictive value beyond that of the individual lipids, and/or TC/HDL-C ratio. ${ }^{20}$

\section{Diabetes Mellitus, GHb, Lipid profiles, and Altitude}

Human physiology is affected in different ways at high altitude. Some studies on non-diabetic subjects at altitude show an increase in fasting glucose and counter-regulatory hormones although other factors like acclimatization or time at altitude modify this rise, but the effect of altitude on diabetes mellitus is unknown. ${ }^{21-23}$ In people who are acclimatized to living at high altitudes, there is an increase in the number of erythrocytes, and consequently an increase in the whole blood total haemoglobin concentration. Individual $\mathrm{GHb}$ values can be influenced by polycythaemia and this might result in a wrong diagnostic classification of the involved patient and cause unnecessary therapeutic interventions. ${ }^{24}$

Moreover, the lower mortality from coronary ischemic disease in populations living at high altitude has been related to an increase of $\mathrm{HDL}$-cholesterol at altitude. ${ }^{25}$ Higher levels of serum HDL have been detected in those who live at high altitudes, and increases in HDL have been observed in a population migrating from lower altitudes to high mountain regions. ${ }^{26-29}$ Previous studies indicate that HDL cholesterol levels are linearly and significantly increased when living at a higher altitude. This fact should be taken into account when comparing cardiovascular risk in populations living at different altitudes. ${ }^{25}$

Keeping this background in mind, the study was designed to see the correlations between blood glucose levels, haemoglobin levels, glycosylated haemoglobin levels, and lipid profiles including AIP, in Type 2 diabetic patients residing at Gangtok. Gangtok is in the state of Sikkim in India and at an altitude of $5800 \mathrm{ft}$ $(1780 \mathrm{~m})$ above sea level.

\section{MATERIALS AND METHODS}

A cross sectional, convenience sample study was carried out over a period of six months in the out patients department of Central Referral Hospital, Gangtok and during this period, a total of 33 male patients with type 2 diabetes, who met the inclusion criteria were selected. The inclusion criteria were as follows: Male patients aged between 40 and 60 years, who were freshly diagnosed with type 2 diabetes, and were living in the Gangtok for a minimum period of one year, prior to the study, and were willing to participate in the study. Diabetic patients who were taking hypogycaemic drugs were excluded as these drugs might effect the plasma lipid profile in these patients. ${ }^{30}$ Ten healthy individuals of the same age and gender, who volunteered, formed the control group. All the selected patients and controls were natives of Gangtok. Only male patients were selected to minimize gender bias on haemoglobin levels.

Fasting blood sample and Post prandial blood samples were obtained by venipuncture from all the selected patients and controls after taking informed consent. Fasting blood sample was used for the estimation of Fasting plasma glucose (FG), Haemoglobin, GHb and lipid profile namely Total Cholesterol (TC), Triglycerides (TG), HDL-Cholesterol (HDL-C) and LDL-Cholesterol (LDL-C), TC/HDL-C ratio, AIP were calculated. Postprandial blood samples were used for the estimation of Postprandial Glucose levels (PPG).

Based on the postprandial glucose levels, the subjects were divided into three groups as follows:

Control (PPG $<140 \mathrm{mg} / \mathrm{dl})(\mathrm{n}=10)$

Group I (PPG $<160-200 \mathrm{mg} / \mathrm{dl})(\mathrm{n}=14)$

Group II (PPG $>200 \mathrm{mg} / \mathrm{dl}) \quad(\mathrm{n}=19)$

Plasma Glucose both in the fasting and the post prandial samples were estimated by enzymatic - glucose 
oxidase-peroxidase method using commercially available kits. ${ }^{31}$ Haemoglobin was estimated by cyanmethhaemoglobin method using whole blood samples. ${ }^{32}$ Total GHb was estimated using the cation-exchange resin kits. ${ }^{33}$ The procedure can be described briefly as follows: a hemolysed preparation of the whole blood is mixed continuously for 5 minutes with a weak binding cation-exchange resin. During this time, non-glycosylated haemoglobin binds to the resin. After the mixing period, a filter is used to separate the supernatant containing the glycohaemoglobin from the resin. The percentage glycohaemoglobin is determined by measuring the absorbance at $415 \mathrm{~nm}$ of the glycohaemoglobin fraction and the total haemoglobin fraction. The ratio of the two absorbencies gives the percent total GHb.

Serum was used for the estimation of Total Cholesterol, ${ }^{34}$ Triglyceride, ${ }^{35}$ and HDL-Cholesterol by enzymatic methods. ${ }^{36}$ LDL-Cholesterol was calculated by using the Friedewald equation ${ }^{37}$. The ratio of TC to HDL-C was also calculated. AIP was calculated as log (TG/HDL-C), with TG and HDL-C expressed in molar concentrations ${ }^{19}$.

\section{Statistical analysis}

The laboratory results were statistically analyzed using SPSS software package. Student t-test was used for comparison of the groups with the control. $P$ values $<0.05$ were considered significant at $5 \%$ level. The Pearson's correlation coefficient $(r)$ was calculated to look for correlations between different parameters within the groups and with the control group.

\section{RESULTS}

Age, blood glucose, $\mathrm{Hb}$, Ghb values of different study groups are presented in Table I. The FG and PPG levels were significantly higher in both the groups when compared to the controls. GHb values in the control group were slightly higher (at $7.61 \% \pm 0.47$ ) than the suggested normal value of $7 \%$ given by the American Diabetic Association ${ }^{13}$. GHb values were significantly more in group 2 than controls. In Group 2, the GHb levels correlated positively with PPG levels $(r=0.92$, $\mathrm{p}<0.001)$.

Table II gives the lipid profile in different study groups. Total Triglyceride levels, the ratio of TC/ HDL- C and AIP were significantly more in Group 2 when compared to the control group. HDL-cholesterol levels were significantly lower in Group 2 when compared to controls.

The analysis for correlations between glucose levels and lipid profiles show, in Group 1, GHb levels correlated positively with Triglycerides $(r=0.65, p<0.01)$ and AIP ( $r=0.62, p<0.01)$. In Group 2, PPG levels and $\mathrm{GHb}$ levels correlated positively with Total cholesterol, LDL cholesterol, TC/HDL-C ratio and AIP (Table III).

Though previous studies have shown that people living at higher altitudes have higher levels of HDL- Cholesterol, such a finding is not seen in the present study.

Table I. Glucose, Haemoglobin and GHb levels

\begin{tabular}{|c|c|c|c|}
\hline & $\begin{array}{l}\text { Control } \\
(n=10)\end{array}$ & $\begin{array}{c}\text { Group } 1 \\
(n=14)\end{array}$ & $\begin{array}{c}\text { Group } 2 \\
(n=19)\end{array}$ \\
\hline AGE (yrs) & $\begin{array}{l}48.77 \\
\pm 6.3\end{array}$ & $\begin{array}{r}50.8 \\
\pm 7.05\end{array}$ & $\begin{array}{l}51.45 \\
\pm 7.65\end{array}$ \\
\hline FG (mg/dl) & $\begin{array}{l}76.8 \\
\pm 9.3\end{array}$ & $\begin{array}{c}110.2 \\
\pm 14.29^{*}\end{array}$ & $\begin{array}{r}123.21 \\
\pm 17.46^{*}\end{array}$ \\
\hline PPG (mg/dl) & $\begin{array}{r}113.7 \\
\pm 10.66\end{array}$ & $\begin{array}{c}176.4 \\
\pm 12.55^{*}\end{array}$ & $\begin{array}{c}266.89 \\
\pm 59.72\end{array}$ \\
\hline $\mathrm{Hb}(\mathrm{mg} / \mathrm{dl})$ & $\begin{array}{r}14.66 \\
\pm 0.86\end{array}$ & $\begin{array}{r}14.81 \\
\pm 0.96\end{array}$ & $\begin{array}{r}14.69 \\
\pm 0.91\end{array}$ \\
\hline $\mathbf{G H b}(\%)$ & $\begin{array}{c}7.61 \\
\pm 0.47\end{array}$ & $\begin{array}{c}8.25 \\
\pm 0.52\end{array}$ & $\begin{array}{c}10.24 \\
\pm 0.80^{*}\end{array}$ \\
\hline
\end{tabular}

Table II. Fasting Lipid Profiles

\begin{tabular}{|c|c|c|c|}
\hline & $\begin{array}{c}\text { Control } \\
(n=10)\end{array}$ & $\begin{array}{c}\text { Group } 1 \\
(n=14)\end{array}$ & $\begin{array}{c}\text { Group } 2 \\
(n=19)\end{array}$ \\
\hline $\begin{array}{l}\text { Total } \\
\text { Cholesterol } \\
\text { (TC) (mg/dl) }\end{array}$ & $\begin{array}{c}158.9 \pm \\
13.1\end{array}$ & $\begin{array}{c}164.79 \pm \\
14.5\end{array}$ & $\begin{array}{c}190.16 \pm \\
30.0\end{array}$ \\
\hline $\begin{array}{l}\text { Total } \\
\text { Triglycerides } \\
\text { (mg/dl) }\end{array}$ & $\begin{array}{l}93.2 \pm \\
16.07\end{array}$ & $\begin{array}{c}101.07 \pm \\
17.4\end{array}$ & $\begin{array}{c}127.95 \pm \\
23.96 \text { * }\end{array}$ \\
\hline $\begin{array}{l}\text { HDL - } \\
\text { Cholesterol } \\
\text { (HDL-C) } \\
\text { (mg/dl) }\end{array}$ & $\begin{array}{c}43.3 \pm \\
2.2\end{array}$ & $\begin{array}{c}39.71 \pm \\
3.02\end{array}$ & $\begin{array}{c}36.18 \pm \\
2.7^{*}\end{array}$ \\
\hline $\begin{array}{l}\text { LDL - } \\
\text { Cholesterol } \\
\text { (mg/dI) }\end{array}$ & $\begin{array}{c}96.96 \pm \\
15.64\end{array}$ & $\begin{array}{c}104.86 \pm \\
13.76\end{array}$ & $\begin{array}{c}128.38 \pm \\
28.1\end{array}$ \\
\hline $\begin{array}{l}\text { TC/ HDL-C } \\
\text { ratio }\end{array}$ & $\begin{array}{c}3.68 \pm \\
0.38\end{array}$ & $\begin{array}{c}4.16 \pm \\
0.38\end{array}$ & $\begin{array}{l}5.62 \pm \\
0.91 *\end{array}$ \\
\hline AIP & $\begin{array}{c}-0.045 \pm \\
0.03\end{array}$ & $\begin{array}{l}0.03 \pm \\
0.097\end{array}$ & $\begin{array}{c}0.17 \pm \\
0.1^{*}\end{array}$ \\
\hline
\end{tabular}

\section{* P value $<0.05$-Significant}

Table III. Correlation values between PPG, GHb with lipid profiles in Group 2

$\begin{array}{ccccc}\text { Total } & \begin{array}{c}\text { LDL- } \\ \text { cholesterol } \\ \text { Cholesterol }\end{array} & \begin{array}{c}\text { TC/HDL- } \\ \text { C ratio }\end{array} & \text { AIP } \\ \text { PPG } & r=0.84 & r=0.85 & r=0.86 & r=0.46 \\ & p<0.001 & p<0.001 & p<0.001 & p<0.05 \\ \text { GHb } & r=0.73 & r=0.76 & r=0.73 & r=0.46 \\ & p<0.001 & p<0.001 & p<0.001 & p<0.05\end{array}$




\section{DISCUSSION}

In clinical practise, the clinician usually compares the reported values with the reference values for interpreting a patient's laboratory result, but the reference values are not specific to where they live..$^{38-41} \mathrm{Un}$ fortunately reference values are obtained only from a population predominantly living in North America and Europe and not from all over the world population. ${ }^{42}$ In the present study, the haemoglobin levels were on the higher side of normal haemoglobin levels in all the groups, in accordance with the altitude they were staying. It has been reported that up to moderate high altitudes, an adaptation mechanism causes increasingly higher numbers of red blood cell and consequently higher haemoglobin production. ${ }^{43,44}$ The reason for this has been attributed to the altitudeinduced decrease in partial pressure of oxygen, which leads to a drop in renal tissue oxygenation. It is hypothesized that this reduction in renal tissue oxygenation stimulates the synthesis and release of erythropoietin (EPO), the principal hormone that regulates erythrocyte (RBC) and haemoglobin production. In turn, an increase in serum EPO concentration stimulates the synthesis of new RBCs in the red bone marrow and also synthesis of heme and haemoglobin. ${ }^{45,46}$

Because of the quantitative increase in haemoglobin concentrations, there was observed concomitant increase in GHb levels above the reference range even in the control group. This suggests that $\mathrm{GHb}$ values can be affected by factors other than of glycaemia. Taking this into consideration laboratories should develop their own reference ranges for $\mathrm{GHb}$, especially in places at higher altitudes. In the present study, significant positive correlation was seen between PPG levels and GHb but it correlated less with FG levels in both the groups. This is similar to findings in Diabetes Control and Complications Trial (DCCT) research group in which $\mathrm{GHb}$ levels correlated more with Mean plasma glucose and correlated less with FG levels. ${ }^{14,47}$ This means Fasting PG should be used with caution as a surrogate measure of mean plasma glucose levels. The PPG levels also correlated positively with Total Cholesterol, LDL-Cholesterol, TC/HDL-C ratio and AIP in Group II. Since Group II consists of patients with PPG levels more than $200 \mathrm{mg} / \mathrm{dl}$, it suggests that higher PPG levels are associated with more atherogenic lipid profiles. This should be remembered while formulating treatment plans and it might be necessary to target the PPG levels also in addition to FG levels. Many investigators have noted a strong correlation between $\mathrm{GHb}$ levels of diabetics with lipids and lipoproteins, but not with HDL cholesterol. ${ }^{48}$ In this study $\mathrm{GHb}$, correlated positively with Triglycerides and AIP in Group I. In Group II, GHb levels correlated positively with Total cholesterol, LDL-Cholesterol, TC/HDL-C ratio and AIP. Since in the calculation of AIP, the Triglyceride levels are also considered, it may prove to be a more valuable adjunct while calculating the overall risk of diabetics for future CAD.

\section{CONCLUSION}

The study points out the importance of each lab establishing its own reference ranges, or if possible to establish the reference range with respect to the altitude. The study shows that there is a need to consider, not only fasting, but also the post prandial glucose levels while formulating treatment plans, as higher PPG levels are associated with more Atherogenic lipid profiles. The study also emphasis the usefulness of Atherogenic Index of Plasma in calculating the risk of complications associated with diabetes mellitus.

\section{REFERENCES}

1. Zubiate M. Diabetes mellitus and high altitude. Diabetologia Croatica 2001; 30:23-28

2. Deepa R, Arvind K, Mohan V. Diabetes and risk factors for coronary artery disease. Curr Sci 2002; 83:1497-505

3. Joshi SR. Diabetes Mellitus. Q Med Rev 2003; 53:2-42

4. Haffner SM. Coronary heart disease in patients with diabetes. N Engl J Med 2000; 342:1040-2

5. Keen H, Clark C, Laakso M. Reducing the burden of diabetes: managing cardiovascular disease. Diab Metab Res Rev 1999; 15:186-96

6. Lowe LP, Liu K, Greenland P, et al. Diabetes, asymptomatic hyperglycaemia and 22-year mortality in black and white men. The Chicago heart association detection project in industry study. Diabetes Care 1997; 20:163-9

7. Malmberg K, Ryden L, Efendic S, et al. Randomized trial of insulin-glucose infusion followed by subcutaneous insulin treatment in diabetic patients with acute myocardial infarction (DIGAMI study): Effects on mortality at 1-year. J Am Coll Cardiol 1995; 26:57-65

8. Intensive blood glucose control with sulphonylureas or insulin compared with conventional treatment and risk of complications in patients with type-2 Diabetes (UKPDS-33). Lancet 1998; 352:837-53

9. Mohan V, Deepa R, Shanthirani S, Premalatha $\mathrm{G}$. Prevalence of coronary artery disease and its relationship to lipids in a selected population in South India: Chennai Urban Population Study (CUPS No.5). J Am Coll Cardiol 2001; 38:682-7

10. Tran HA, Silva D, Petrovsky N. Case study: potential pitfalls of using haemoglobin $\mathrm{A} 1 \mathrm{C}$ as the sole measure of glycemic control. Clin Diabetes 2004; 22:141-3

11. Goldstein DE, Little RR, Wiedmeyer HM, England JD, McKenzie EM. Glycated haemoglobin: methodologies and clinical applications. Clin Chem 1986; 32:B64-70

12. DCCT Research Group: The effect of intensive treatment on the development and progression of long term complications in the diabetes control in insulin dependent diabetes 
mellitus. N Engl J Med 1993; 329:977-86

13. Goldstein D, Lorenz RA, Malone J, Nathan DM, Peterson CM. Tests of glycemia in diabetes. Diabetes Care 2000; 23:S80-82

14. Lynn B, Chen CP, Sacks DB. Effects of haemoglobin variants and chemically modified derivatives on assays for glycohaemoglobin. Clin Chem 2001; 47:153-63

15. Koskinen P, Manttari M, Manninen V, et al. Coronary heart disease incidence in NIDDM patients in the Helsinki Heart Study. Diabetes Care 1992; 15:820-5

16. Laakso M, Lehto S, Penttila I, Pyorala K. Lipids and lipoproteins predicting coronary heart disease mortality and morbidity in patients with non-insulin-dependent diabetes. Circulation 1993; 88:1421-30

17. Manninen V, Tenkanen L, Koskinen P, et al. Joint effects of serum triglyceride and LDL cholesterol and HDL cholesterol concentrations on coronary heart disease risk in the Helsinki Heart Study. Implications for treatment. Circulation 1992; 85:37-45

18. Tan MH, Johns D, Glazer NB. Pioglitazone reduces atherogenic index of plasma in patients with type 2 diabetes. Clin Chem 2004; 50:1184-8

19. Dobiasova M, Frohlich J. The plasma parameter log (TG/HDL-C) as an atherogenic index: correlation with lipoprotein particle size and esterification rate in apoB-lipoproteindepleted plasma (FERHDL). Clin Bio chem 2001; 34:583-8

20. Dobiasova M. Atherogenic Index of Plasma [Log (Triglycerides/HDL-Cholesterol)]: Theoretical and Practical Implications. Clin Chem 2004; 50:1113-5

21. Admetlla J, Leal C, Ricart A. Diabetes and Mountain Sports. Institut d'Estudis de Medicina de Muntanya, Muntaner, Barcelona. Spain. 2001, 229-36.

22. Sutton JR, Viol GW, Gray GW, McFadden MD, Keane PM. Renin, aldosterone, electrolyte and cortisol responses to hypoxic decompression. Jour Appl Physiol 1977; 43:421-4

23. Favier Roland JM. The effects of altitude on the hormonal responses to exercise. In Warren MP. Sports Endocrinology Chap 21. Humana press Inc, Totowa, NJ. 2000; 371-89.

24. Leon AC, González DA, Méndez LP, et al. Leptin and Altitude in the Cardiovascular Diseases. Obes Res 2004; 12:1492-8

25. Baumann GH, Katzensteiner S, Schnedl W, et al. Comparative evaluation of three assay sys-tems for automated determination of haemoglobin A1c. Clin Chem 1997; 43:511-7

26. Coello SD, León AC, Ojeda FB, et al. High density lipoprotein cholesterol increases with living altitude. Int J Epidemiol 2000; 29:6570

27. Sharma S. Clinical, biochemical, electrocardiographic and noninvasive hemodynamic assessment of cardiovascular status in natives at high to extreme altitudes (3000-5500 m) of the Himalayan region. Indian Heart J 1990; 42:375-9

28. Aitbaev KA. The levels of high density lipoprotein and other lipids in the native population of the mountain region of Kirghizia. Vopr Med Khim 1985; 1:58-61 [Russian]

29. Aitbaev KA, Madaminov I, Meimanaliev TS, Shleifer EZ, Kim NM. Study of the effect of migration to high-mountain regions on the blood lipoprotein system. Kosm Biol Aviakosm Med 1990; 24:45-6 [Russian]

30. Lund, Soren S, Tarnow, Frandsen et al. Impact of metformin versus the prandial insulin secretagogue, repaglinide, on fasting and postprandial glucose and lipid responses in non-obese patients with type 2 diabetes.

Eur J Endocrinol 2008;158:35-46

31. Sacks DB. Carbohydrates. In: Burtis CA, Ashwood ER eds. Teitz Textbook of clinical chemistry, 3rd edition, Philadelphia: Saunders, 1999: 750-4

32. Drabkin DL, Austin JM. Spectrometric studies and spectrometric constants for common haemoglobin derivatives in human, dog, and rabbit blood. J Biol Chem 1932; 98:719

33. Trivelli LA, Ranney PH, Lai HT. Haemoglobin components in patients with diabetes mellitus. N Engl J Med 1971; 284:353

34. Zlatkis A, Zak B, Boyle A. A new method for the direct determination of cholesterol. J Lab Clin Med 1953; 41:483

35. McGowan MW, Artiss JD, Standbergh DR, Zark B. A peroxidase coupled method for the colorimetric determination of serum triglycerides. Clin Chem 1983; 29:538-9

36. Burstein M, Scholnick HR, Morfin R. Estimation of HDL-C. J Lipid Res 1970; 19:583-93

37. Rifai N, Bachorik SP, Albers JJ. Lipids, lipoproteins, and apolipoproteins. In: Burtis CA, Ashwood ER, Border BG eds. Teitz Fundamentals of Clinical Chemistry 5th edition. Philadelphia: Saunders, 2001: 488

38. Castro OL, Haddy T, Rana SR. Age- and sexrelated blood cell values in healthy black Americans. Public Health Rep1987; 102:232-7

39. Kelly A, Munan L. Haematologic profile of natural populations: Red cell parameters. $\mathrm{Br}$ J Haematol 1977; 35:153-60

40. Tsang CH, Lazarus R, Smith W, et al. Hematological indices in an older population sample: Derivation of healthy reference values. Clin Chem 1998; 44:96-101

41. Kaya H, Kiki Ý, Akarsu E, et al. Hematological values of healthy adult population living at moderate altitude $(1869 \mathrm{~m}$, Erzurum, Turkey) Turk J Haematol 2000; 17(3) :123-8

42. Saxena S, Wong ET. Heterogeneity of common hematologic parameters among racial, ethnic, and gender subgroups. Arch Pathol Lab Med 1990; 114:715-9

43. Hurdato A, Merino C, Delgrado A. Influence of anoxemia on hematopoetic activity. Arch 
Intern Med 1945; 75:284-323

44. Ruiz-Arguelles GJ, Sanchez-Medal L, Loria A, Piedras J, C6rdova MS. Red cell indices in normal adults residing at altitudes from sea to 2670 meters. Am J Hematol 1980; 8:26571

45. Porter DL. Physiology of erythropoietin production. Semin Hematol1994; 31:112-21

46. Richalet JP, Souberbielle JC, Antezana AM, et al. Control of erythropoiesis in humans during prolonged exposure to the altitude of 6,542m. Am J Physiol 1994; 266:R756-64

47. Rohlfing $\mathrm{CL}$, Wiedmeyer $\mathrm{HM}$, Little RR, et al. Defining the relationship between plasma glucose and $\mathrm{HbA}(1 \mathrm{c})$ : analysis of glucose profiles and $\mathrm{HbA}(1 \mathrm{c})$ in the Diabetes Control and Complications Trial. Diabetes Care 2002; 25:275-8

48. Barrett-Connor E, Criqui MH, Witztum JL, Philippi T, Zettner A. Population-based study of glycosylated haemoglobin, lipids, and lipo proteins in nondiabetic adults. Arteriosclero sis $1987 ; 7: 66-70$ 